ORIGINAL ARTICLE

\title{
A randomised controlled intervention study on prevention of work related skin problems among gut cleaners in swine slaughterhouses
}

\author{
M-A Flyvholm, K Mygind, L Sell, A Jensen, K F Jepsen
}

Occup Environ Med 2005;62:642-649. doi: 10.1136/oem.2004.016576

See end of article for authors' affiliations

Correspondence to:

DrM-A Flyvholm, National

Institute of Occupational

Health, Lersø Parkallé 105,

DK-2100 Copenhagen,

Denmark; maf@ami.dk

Accepted 18 March 2005

\begin{abstract}
Aims: To evaluate the effect of an intervention to reduce work related skin problems in gut cleaning departments in Danish swine slaughterhouses. The intervention consisted of an evidence based prevention programme and a documented method for implementation.

Methods: Randomised controlled intervention study with a one year follow up. The intervention included educational activities and evidence based recommendations. The effect of the intervention was evaluated by telephone interviews using a standardised questionnaire based on the Nordic Occupational Skin Questionnaire (NOSQ-2002) with modified and additional questions on exposure, preventive measures, information, and discussions on prevention of skin problems, etc.

Results: A total of 644 (87.5\%) responded at the baseline interview and $622(71.6 \%)$ at the one year follow up interview. A total of 495 participated in both interviews (67.3\%). In the intervention departments the frequency of eczema on hands or forearms within the past three months at follow up was reduced significantly from $56.2 \%$ at baseline to $41.0 \%$ at follow up, while a slight non-significant increase was observed in the comparison departments (from $45.9 \%$ to $50.2 \%$ ). The intervention activities resulted in more frequent use of protective gloves in general and the use of cotton gloves worn underneath rubber and plastic gloves. At follow up three times as many in the intervention departments used the recommended high fat skin care products introduced as part of the intervention activities. At follow up, discussion of skin problems was increased in the intervention group while no changes were observed in the comparison group.

Conclusions: A significant $27 \%$ relative reduction of occupational eczema in a high risk group was feasible through implementation of an evidence based prevention programme.
\end{abstract}

$\mathrm{F}$ or many years occupational skin diseases have been the most frequent recognised work related diseases in many industrialised countries. ${ }^{12}$ Despite considerable knowledge on risk factors and prevention of occupational skin diseases obtained from clinical, epidemiological, and experimental studies, the eczema frequency in the working population remains high and has even increased in some populations. $^{2-4}$ Occupational skin diseases are often chronically relapsing, ${ }^{5}$ they affect workers early in their working age, ${ }^{36}$ impair their health related quality of life, and the social and economic impacts are often severe. ${ }^{7-9}$ Wet work occupations, such as the healthcare sector and the food processing industry represent major risk groups. ${ }^{6}$ A study from Japan made in 1983 found skin symptoms in $65.1 \%$ of 527 workers in four poultry slaughterhouse workers: most symptoms were caused by wet work. ${ }^{10}$

Different kinds of evidence based prevention programmes have with more or less success been introduced in different occupations. ${ }^{11-15}$

The working conditions in the food processing industry often involve wet work, various skin irritants, allergens (from, for example, foods, soaps, and disinfectants), and high hygienic demands. The work in the gut cleaning departments in swine slaughterhouses is characterised by mostly manual work, where hands and forearms are exposed to water, contents from the guts, gastric juice, salt, and relatively frequent hand washing. During the gut cleaning process gloves easily get wet on the inside and at specific procedures they reduce work speed. Thus gloves are only of limited acceptance. The gut cleaning process in itself does not allow for any considerable reduction of wet work by automation, either now or in the near future.
The purpose of the present study was to evaluate the effect of a one year workplace intervention to reduce work related skin problems in gut cleaning departments in Danish swine slaughterhouses using a randomised intervention study design including both an intervention group and a comparison group. The workplace intervention consisted of an evidence based prevention programme and a documented method for implementation.

The evidence based prevention programme consisted of recommendations on prevention of work related skin problems in wet work occupations. These recommendations were compiled on the basis of prevention programmes published earlier ${ }^{12-16}$ and on a literature study carried out as part of the present project (published in Danish in order to make the tools used available for national occupational health consultants). ${ }^{17}$ The final version of these recommendations is shown in box 1 .

The methods for implementation were primarily based on a study among wet work employees in old people's homes. ${ }^{15}$ After a five month intervention period Held et al showed significant changes in skin symptoms, information level on skin care, and behaviour in the intervention group compared to the control group. No significant difference was observed for self-reported skin problems.

The aim of this paper is to describe the characteristics of the study population and the results, with focus on changes in eczema and use of preventive measures.

\section{METHODS}

Study population

The study population included all Danish gut cleaners from 18 swine slaughterhouses, each having a separate gut 
Box 1: Evidence based recommendations on prevention of work related skin problems in wet work occupations revised according to results and experiences obtained in the present study*

- Avoid or reduce wet and dirty manual working procedures

- Use protective gloves for wet and dirty working procedures, if possible

- Protective gloves must be intact, clean, and dry inside and must be worn on clean, dry, and well cared for skin

- Use fabric gloves, e.g. cotton gloves underneath the protective gloves

- Use a skin care product when needed during the working day and always after work

- Use a skin care product before wet and dirty working procedures if you do not use protective gloves

- The skin care product should have a high content of petrolatum and a low content of water

- Do not wear finger rings, jewellery, or wristwatch on hands or forearms during work

- Wash your hands in cool water, rinse off the soap thoroughly, and dry your hands carefully with a soft material afterwards

- When there is no visible contamination of the hands, hand washing can with advantage be substituted by an alcohol based hand disinfectant

- Protective gloves, hand soaps, skin care products, and hand disinfectants should be without known irritant and allergic substances or with lowest possible content of them

*Compared to the recommendations included in the prevention programme used in the present study a recommendation on avoiding use of hand disinfectants has been substituted by the recommendation "When there is no visible contamination of the hands, hand washing can with advantage be substituted by an alcohol based hand disinfectant". The recommendation "Use a skin care product before wet and dirty working procedures, if you do not use protective gloves" was added.

cleaning department. These departments, which were located in different cities, were organised in one company; their production procedures were similar, but each department was attached to the local safety organisation of the respective slaughterhouse, leading to slightly different safety cultures. The 18 departments had a total of 736 employees in January 2002 and 748 employees in January 2003. A group of 121 persons who were employed in January 2002, but had stopped working in the gut cleaning departments before January 2003, were also included in the telephone interviews at follow up.

Figure 1 outlines the number of participants at baseline and follow up divided into the intervention and comparison groups.

The intervention group consisted of six randomly allocated gut cleaning departments; the remaining departments made up the comparison group. The 12 comparison departments included at baseline were reduced to 11 at follow up due to a planned closing down in the study period. Employees from the closed department were transferred to another department in the comparison group.

\section{Non-responders}

At baseline 92 employees (12.5\%) did not participate in the telephone interview: 40 were not contacted due to absence of telephone numbers, 8 declined, 19 were not reached after several attempts, and the remainder did not participate for other reasons, including language barriers. At follow up 247 employees $(28.4 \%)$ did not participate in the telephone interview: 81 were not contacted (79 without telephone numbers, one had died, and one had left the country), 51 declined, 79 were not reached after several attempts, and the remainder did not participate for other reasons (language barriers, hospital stays, or left the country). A drop-out analysis on those responding in the first telephone interview but not in the second telephone interview $(n=148)$ showed that this group were slightly younger and had worked as gut cleaners for a shorter time. No differences in the reporting of eczema within the past three months were observed.

\section{Intervention}

The prevention strategy consisted of a two part concept, with an evidence based prevention programme giving recommendations for prevention of work related skin problems in wet work occupations, and a documented method for implementation.

The evidence based prevention programme used in the present study was based on prevention programmes used or published from previous studies, ${ }^{12-16}$ and a literature study on risk factors for occupational skin diseases in wet work occupations. ${ }^{17}$ The prevention programme included both recommendations aimed at the management and recommendations on work routines aimed at the employees (see box 1).

The essence of the implementation method was that in order to change habits at the shop floor it is necessary to involve the whole organisation. ${ }^{18}$ A local project group with representatives from all levels of the organisation were trained to start the process of establishing an occupational health and safety management system focused on skin risks. The educational programme included both knowledge about the origin of and protection against eczema and the principles of the occupational health and safety managing system. The local project group included 2-5 gut cleaners who afterwards would act as role models, practising skin protection and adequate working routines (that is, embodying good habits) and supervise their colleagues. The educational programme consisted of two full working days with one month in between, and were planned and carried out by a consultant from the Occupational Health Service and a researcher from the National Institute of Occupational Health. The educational activities included lectures, discussions, reflection, homework, and feedback.

\section{Study design}

The study was a field study and designed as a randomised controlled intervention study, including both an intervention group and a comparison group.

A one year follow up was chosen in order to eliminate the effect of seasonal variations in both the activity of the skin diseases and the exposures. This also ensured that the intervention was implemented before follow up.

This study was not subject to the ethical committee notification system as no medical procedures were included.

The distribution of the different departments into intervention or comparison group was not announced to the employees until after the baseline interviews. The follow up interviews were carried out after a period of one year (March 2003). The educational activities were carried out within two months after baseline. Data for the process evaluation were collected at the end of the educational programme, at a 3 


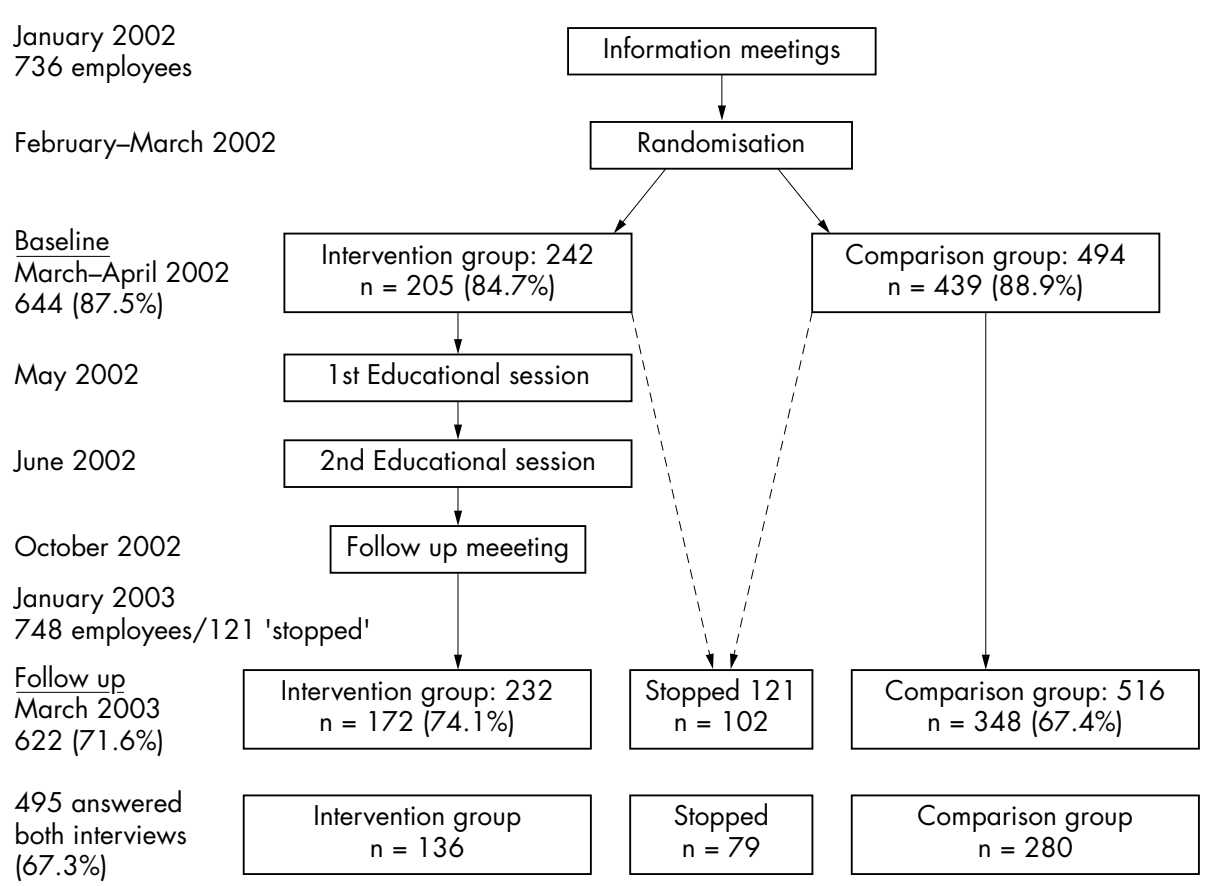

Figure 1 Flow chart for the intervention study, showing the study population divided into an intervention group, a comparison group, and a group of those who had stopped being gut cleaners at follow up, with time frame and response rates.

month follow up meeting (ad hoc questionnaires and written procedures), and by structured interviews with members of the local project groups shortly after the follow up telephone interviews were carried out. Results from the process evaluation studying the implementation of the intervention will be reported elsewhere.

\section{Measurements}

Both the intervention group and the comparison group were examined by a thorough telephone interview at baseline (March to April 2002) immediately before the intervention activities started and after one year (March 2003). All employees were informed about the project by the local management and received a written introduction explaining the overall set-up, focusing on the anonymity of the employee and that participation was voluntary. It was emphasised that no individual data would be passed on to the management or the Occupational Health Service.

Medical examinations were not conducted in this study as continuous observations could not be performed.

\section{Questionnaire}

The questionnaire used for the telephone interviews was based on a standardised questionnaire for investigation of work related skin diseases and exposure-NOSQ-2002, developed by a Nordic working group. ${ }^{19} 20$ This questionnaire is available in English and has been translated into Danish, Swedish, Finnish, Icelandic, and Norwegian. The use of a standardised questionnaire allows comparison with results from other studies. Origin of the questions and question sets included in NOSQ-2002, as well as validations have been described previously. Of special importance for the present

Table 1 Characteristics of the study population divided into intervention group, comparison group, and those not working as gut cleaners at follow up

\begin{tabular}{|c|c|c|c|c|}
\hline & $\begin{array}{l}\text { Intervention group } \\
(\mathrm{n}=172)\end{array}$ & $\begin{array}{l}\text { Comparison group } \\
(n=348)\end{array}$ & $\begin{array}{l}\text { Stopped as gut cleaners } \\
\text { ( } \mathrm{n}=102)\end{array}$ & $\begin{array}{l}\text { Total } \\
(n=622)\end{array}$ \\
\hline \multicolumn{5}{|l|}{ Gender } \\
\hline Men & $66.3 \%(114)$ & $64.1 \%(223)$ & $62.7 \%(64)$ & $64.5 \%(401)$ \\
\hline Women & $33.7 \%(58)$ & $35.9 \%(125)$ & $37.3 \%(38)$ & $35.5 \%(221)$ \\
\hline \multicolumn{5}{|l|}{ Age } \\
\hline Average & 36.1 years & 37.8 years & 38.5 years & 37.4 years \\
\hline Median & 35 years & 37 years & 36 years & 37.0 years \\
\hline Range & $17-62$ years & $17-66$ years & $17-67$ years & 17-67 years \\
\hline Below 40 years & $68.0 \%(117)$ & $58.3 \%(203)$ & $64.7 \%(66)$ & $62.1 \%(386)$ \\
\hline 40 years or older & $32.0 \%(55)$ & $41.7 \%(145)$ & $35.3 \%(36)$ & $37.9 \%(236)$ \\
\hline Seniority & $(n=172)$ & $(n=345)$ & $(n=56)$ & $(n=573)$ \\
\hline Average & 11.3 years & 12.6 years & 5.0 years $^{* * *}$ & 11.4 years \\
\hline Median & 7.8 years & 8.8 years & 1.8 years & 7.3 years \\
\hline Range & $1-45.2$ years & $0.4-46.2$ years & $0.8-44.8$ years & $0.4-46.2$ years \\
\hline $0-4$ years & $37.2 \%(64)$ & $35.4 \%(112)$ & $71.4 \%^{* *}(40)$ & $39.4 \%(226)$ \\
\hline 5-14 years & $31.4 \%(54)$ & $29.0 \%(100)$ & $19.6 \%(11)$ & $28.8 \%(165)$ \\
\hline Over 15 years & $31.4 \%(54)$ & $35.7 \%(123)$ & $8.9 \%^{* *}(5)$ & $31.8 \%(182)$ \\
\hline
\end{tabular}

Where appropriate, results expressed as \% (number).

** Significant difference between intervention and comparison and "stopped as gut cleaners" $(p<0.01)$.

***Significant difference between intervention and comparison and "stopped as gut cleaners" $(p<0.001)$. 
study is that validation studies have shown self-report hand eczema to be in accordance with dermatological evaluation. Symptom based hand eczema diagnosis in questionnaires can be more sensitive, but has proved more inconsistent compared to self-report hand eczema. ${ }^{19}{ }^{20}$ Questions on work and exposure were trade modified versions incorporating the specific exposures related to gut cleaning. Additional questions on factors such as exposure, preventive measures, safety culture, and knowledge of and discussions on prevention of skin problems were included in order to obtain further information on the implementation and effects of the intervention.

The questionnaire included question sets on background information, eczema, urticaria, skin symptoms, atopy, exacerbating factors, exposure, use of preventive measures (gloves and skin care products), and information on and knowledge about prevention of occupational skin problems.

The Survey Unit at the Institute of Social Research, Copenhagen, Denmark, conducted the telephone interviews and data entry.

The case definition for eczema was: eczema on hands or forearms within the past three months based on questions D1, D2, and D5 in NOSQ-2002.

\section{Statistical analysis}

To evaluate the effectiveness of the intervention, different statistical tests were carried out. Most important, key variables like eczema and use of gloves and skin care products were measured before and after intervention and compared using a test for comparing two paired proportions, based on the Normal distribution. ${ }^{21}$ The $\chi^{2}$ test was used for testing independence of categorical variables. Probability was recognised as significant if the level of significance was less than $0.05 .^{21} 22$

\section{RESULTS}

At baseline a total of $644(87.5 \%)$ employees participated in the telephone interview carried out in March and April 2002. The response rate was $84.7 \%$ in the intervention group and $88.9 \%$ in the comparison group. At follow up in March 2003 a total of $622(71.6 \%)$ participated in the telephone interview. Among the 748 employees working in the gut cleaning departments at follow up, $520(69.5 \%)$ participated in the telephone interview, $74.1 \%$ in the intervention group and $67.4 \%$ in the comparison group. Among the 121 who had stopped working as gut cleaners between baseline and follow up, $102(84.3 \%)$ participated in the follow up interview (see fig 1). A total of 495 participated in both interviews (67.3\%).

Characteristics of the study population divided into intervention group, comparison group, and the group who had stopped working as gut cleaners are shown in table 1 . In general two thirds were men and two thirds were below 40 years of age; only minor differences between the intervention group and the comparison group were observed. At follow up fewer in the intervention group and more in the comparison group were above 40 years of age (not significant).
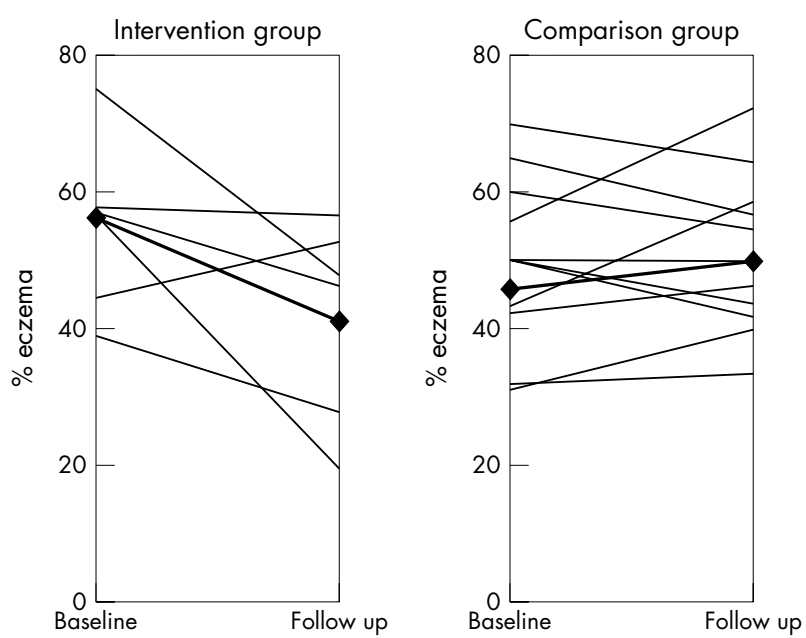

Figure 2 Changes in frequency of eczema on hands or forearms within the past three months from baseline to follow up for the intervention and the comparison groups. Solid lines represent the change in a single department and bold lines with diamonds represent changes within each group.

The time working as a gut cleaner was nearly the same in the intervention group and the comparison group (11.3 and 12.6 years) but was only 5.0 years among those no longer working as gut cleaners $(\mathrm{p}<0.001)$. Compared to the participants still employed in the gut cleaning departments at follow up, twice as many in the group no longer employed had been working as a gut cleaners for less than four years $(71.4 \%)$, and only $8.9 \%$ had been working as a gut cleaners for more that 10 years $(\mathrm{p}<0.05)$.

No significant differences between the groups were seen for self-reported lifetime prevalence of atopic dermatitis, hay fever, and asthma. On average $13.9 \%$ reported having had atopic dermatitis (Question S5a from NOSQ-2002) compared with $9.1 \%$ among the group no longer working as gut cleaners. Hay fever and asthma were reported by $19.1 \%$ and $10 \%$ respectively, with a slightly higher frequency among those no longer working as gut cleaners $(24.5 \%$ and $14.7 \%)$.

\section{Eczema}

At baseline $66.8 \%$ reported having had eczema on hands or forearms within the past year and $50.7 \%$ within the past three months. All results presented in the following are combined figures for eczema on hands or forearms as more than half of those with eczema within the past three months stated that they have had eczema on both hands and forearms.

Despite the random allocation of departments to the intervention group and the comparison group, a significant difference in frequency of eczema on hands or forearms within the past three months was observed at baseline, with $58.9 \%$ in the intervention group and $46.5 \%$ in the comparison

Table 2 Eczema on hands or forearms within the past three months for employees participating at both baseline and follow up

\begin{tabular}{|c|c|c|c|c|c|c|}
\hline & \multicolumn{2}{|c|}{$\begin{array}{l}\text { Intervention group } \\
(\mathrm{n}=136)\end{array}$} & \multicolumn{2}{|c|}{$\begin{array}{l}\text { Comparison group } \\
(n=280)\end{array}$} & \multicolumn{2}{|c|}{$\begin{array}{l}\text { Stopped as gut cleaners } \\
(\mathrm{n}=79)\end{array}$} \\
\hline & Baseline & Follow up & Baseline & Follow up & Baseline & Follow up \\
\hline $\begin{array}{l}\text { Eczema on hands or forearms }<3 \text { months } \\
\text { Relative change } \%\end{array}$ & \multicolumn{2}{|c|}{$-27.0 \%+(p<0.005)$} & \multicolumn{2}{|c|}{$+9.4 \%$ (not significant) } & \multicolumn{2}{|c|}{$-69.8 \%+(p<0.005)$} \\
\hline
\end{tabular}

Results expressed as \% (number)

"Significant difference between intervention and comparison and "stopped as gut cleaners" $(p<0.05)$

** Significant difference between intervention and comparison and "stopped as gut cleaners" $(p<0.01)$.

†Significant difference between baseline and follow up. 
group ( $\mathrm{p}<0.01$ ). The eczema frequency in each department varied from $37.5 \%$ to $68.6 \%$ without the difference being significant, and among the comparison departments the eczema frequency varied significantly from $34.9 \%$ to $69.4 \%$. Further analysis revealed that at one of the comparison departments, the use of gloves was more frequent; if this department was left out of the analysis, the differences in the frequency of eczema between the remaining comparison departments were no longer significant.

A total of 495 employees participated in both the baseline interview and the follow up interview. Based on information from the follow up interview this group could be divided into an intervention group (136 persons), a comparison group (280 persons), and a group no longer working as gut cleaners (79 persons). The following results on the effect of the intervention activities and changes from baseline to follow up are based on those participating in both interviews.

In the intervention group the frequency of eczema on hands or forearms within the past three months was $56.2 \%$ at baseline and $41.0 \%$ at follow up. This relative reduction of $27.0 \%$ was highly significant $(\mathrm{p}<0.005)$ ( see table 2 ). For the comparison group a minor non-significant increase from $45.9 \%$ at baseline to $50.2 \%$ at follow up was observed. For the group no longer employed as gut cleaners the eczema frequency was significant-a relative reduction of nearly $70 \%$ (from $60.3 \%$ at baseline to $18.2 \%$ at follow up; $\mathrm{p}<0.005)$. Among those in the intervention group reporting eczema at baseline, 53\% reported eczema at follow up and $47 \%$ reported no eczema at follow up; among those with no eczema at baseline, $25 \%$ reported eczema at follow up. For the intervention group, $67 \%$ of those with eczema at baseline reported eczema at follow up and 33\% no eczema; 37\% with no eczema at baseline reported eczema at follow up. Among those who had stopped working as gut cleaners at follow up, $22 \%$ reported eczema both at baseline and follow up, $78 \%$ had cleared eczema at follow up, and only $10 \%$ with no eczema at baseline reported eczema at follow up.

Changes in eczema frequency from baseline to follow up divided into the single departments in the intervention group and the comparison group are illustrated in fig 2. In the intervention group, four of six departments had a significant reduction from baseline to follow up $(p<0.001, p<0.01$, and $\mathrm{p}<0.05)$. For the two remaining intervention departments and all the comparison departments the changes from baseline to follow up were not significant.

\section{Preventive measures}

Questions on the use of gloves were included in both interviews. At baseline about $40 \%$ reported present use of gloves at work with no significant differences between the intervention and the comparison group. From baseline to follow up the use of gloves increased to $47.1 \%$ in the intervention group and decreased to $37.5 \%$ in the comparison group, but these changes were not significant. At follow up the glove use in the intervention departments were significantly higher than in the comparison departments (see table 3).

Use of cotton gloves under rubber or plastic gloves was one of the preventive measures introduced. At follow up a significant increase of almost five times in the use of cotton gloves under protective gloves was reported from the intervention group. A more moderate but still significant increase was reported from the comparison group (see table 3).

Questions on the use of skin care products were also included in both interviews. The intervention activities caused the company to introduce a better selection of skin care products with high content of petrolatum for both the intervention and the comparison departments. Thus questions on changing skin care products within the past year were included in the follow up interview. At baseline, $60.0 \%$ of the employees reported use of skin care products at work; the frequency was significantly higher in the intervention group $(69.1 \%)$ than in the comparison group $(55.0 \%)$ $(p<0.05)$. At follow up the use of skin care products increased in both groups, although it was still significant more frequent in the intervention group $(72.1 \%$ and $60.2 \%$ respectively; $\mathrm{p}<0.05$ ) (see table 4 ).

In the intervention group 80 persons used skin care products, both at baseline and at follow up; at follow up 14 had stopped and 18 were new users. For the comparison group, 126 persons used skin care products both at baseline and at follow up; at follow up 28 stopped and 42 were new users. This suggests that it may be a matter of which skin care products the employees are using. At follow up about three times as many in the intervention group reported having changed skin care products within the past year (35.9\% in the intervention group; $13.0 \%$ in the comparison group; $\mathrm{p}<0.05)$. When asked specifically about use of the new skin care products added to the company supply, two of the three products were used significantly more frequently in the intervention departments.

Questions on information and discussions on prevention of skin problems in the workplace were included to provide a measure on changes in the awareness of the topics included in the intervention activities. At baseline, 55.2\% reported that they had previously received information on the prevention of skin problems; this was more frequent in the intervention

Table 3 Self-reported use of protective gloves and cotton under-gloves at baseline and follow up

\begin{tabular}{|c|c|c|c|c|c|c|c|c|}
\hline & \multicolumn{2}{|c|}{$\begin{array}{l}\text { Intervention group } \\
(n=136)\end{array}$} & \multicolumn{2}{|c|}{$\begin{array}{l}\text { Comparison group } \\
(\mathrm{n}=280)\end{array}$} & \multicolumn{2}{|c|}{$\begin{array}{l}\text { Stopped as gut cleaners } \\
(\mathrm{n}=79)\end{array}$} & \multicolumn{2}{|l|}{$\begin{array}{l}\text { Total } \\
(n=495)\end{array}$} \\
\hline & Baseline & Follow up & Baseline & Follow up & Baseline & Follow up & Baseline & Follow up \\
\hline $\begin{array}{l}\text { Use gloves at work at the moment (EI) } \\
\text { Relative change \% }\end{array}$ & \multicolumn{2}{|c|}{$+20.8 \%$ (not significant) } & \multicolumn{2}{|c|}{$-13.2 \%$ (not significant) } & \multicolumn{2}{|l|}{ n.r. } & \multicolumn{2}{|l|}{ n.r. } \\
\hline $\begin{array}{l}\text { Use cotton gloves under rubber or plastic } \\
\text { gloves (E2) }\end{array}$ & $\mathrm{n}=109$ & $\mathrm{n}=96$ & $\mathrm{n}=220$ & $\mathrm{n}=200$ & $\mathrm{n}=57$ & - & $n=386$ & - \\
\hline Relative change $\%$ & \multicolumn{2}{|c|}{$+465.2 \%(p<0.001) \dagger$} & \multicolumn{2}{|c|}{$+59.1 \%(p<0.05) \dagger$} & \multicolumn{2}{|c|}{ n.r. } & \multicolumn{2}{|c|}{ n.r. } \\
\hline Changed glove type the last year & n.d. & $13.5 \%(13)$ & n.d. & $7.4 \%(15)$ & n.d. & n.r. & n.d. & n.r. \\
\hline
\end{tabular}

Where appropriate, results expressed as \% (number).

*Significant difference between intervention and comparison and "stopped as gut cleaners" $(p<0.05)$.

†Significant difference between baseline and follow up.

n.r., not relevant.

n.d., no data; the question was not included in the baseline survey. 
Table 4 Use of skin care products at baseline and follow up and changing skin care products at follow up

\begin{tabular}{|c|c|c|c|c|c|c|c|c|}
\hline & \multicolumn{2}{|c|}{$\begin{array}{l}\text { Intervention group } \\
(n=136)\end{array}$} & \multicolumn{2}{|c|}{$\begin{array}{l}\text { Comparison group } \\
(\mathrm{n}=280)\end{array}$} & \multicolumn{2}{|c|}{$\begin{array}{l}\text { Stopped as gut cleaners } \\
(n=79)\end{array}$} & \multicolumn{2}{|l|}{$\begin{array}{l}\text { Total } \\
(n=495)\end{array}$} \\
\hline & Baseline & Follow up & Baseline & Follow up & Baseline & Follow up & Baseline & Follow up \\
\hline $\begin{array}{l}\text { Use skin care products } \\
\text { at work }\end{array}$ & $69.1 \% *(94)$ & $72.1 \% *(98)$ & $55.0 \%(154)$ & $60.2 \%(168)$ & $62.0 \%(49)$ & n.r. & $60.0 \%(297)$ & n.r. \\
\hline
\end{tabular}

Results expressed as \% (number).

"Significant difference between intervention and comparison and "stopped as gut cleaners" $(p<0.05)$.

n.r., not relevant.

group than in the comparison group $(60.3 \%$ and $52.9 \%$; not significant). At follow up a significantly higher number in the intervention group $(76.1 \%, \mathrm{p}<0.01)$ than in the comparison group $(62.3 \%)$ reported that they had received information on the prevention of skin problems (see table 5). Although a significant increase $(\mathrm{p}<0.005)$ was observed in both groups ( $26.2 \%$ and $17.8 \%$ respectively), this was only reflected in the eczema frequency in the intervention group.

On average, $56.3 \%$ reported that prevention of skin problems was discussed in the workplace at baseline, with only a minor difference between the intervention group and the comparison group. At follow up this was increased by $40 \%$ in the intervention group $(\mathrm{p}<0.005)$, with no change in the comparison group (see table 5 ). Thus the question "Are skin problems discussed at your workplace?" may be a better tool to measure activities and reflection initiated at the workplace as a result of the intervention activities; that is, this question can be seen as an indicator for implementation of the intervention activities.

\section{DISCUSSION}

The overall result from the present study was a significant $27 \%$ relative reduction in the number of cases of self-reported eczema on hands or forearms within the past three months in the intervention group; thus the frequency of eczema was reduced from $56.2 \%$ at baseline to $41.0 \%$ at one year follow up. Several preventive habits included in the intervention activities, such as use of gloves and use of more suitable skin care products, were improved in the intervention group. The group no longer working as gut cleaners at follow up can be seen as "an internal comparison group" — exposed at baseline and not at follow up. The eczema frequency in this group was reduced from $60.3 \%$ to $18.2 \%$, a level comparable to the $13 \%$ seen among a representative sample of Danish wage earners. $^{34}$

The response rates were $87.5 \%$ at baseline, $71.6 \%$ at follow up, and $67.3 \%$ who participated in both interviews, which were considered to be satisfactory. The response rates were comparable in the intervention group and the comparison group, although slightly lower at follow up in the comparison group, possibly due to the lack of intervention activities in this group.

The observed differences in the eczema frequency within the comparison group at baseline seem to be due to differences in the use of gloves in a single comparison department. When controlling for this factor, the difference between the comparison departments was no longer significant.

The use of questionnaires only for assessing the eczema frequency is a limitation of the present study; no clinical examinations were included. However, a higher response rate could be expected by using questionnaires and telephone interviews compared to inviting participants from geographically spread departments with shift work to attend clinical examinations. Furthermore, use of questionnaires allows for collection of additional data on exposure and preventive measures. As the same questions have been used at baseline and follow up, and in both the intervention and the comparison groups, the possible error is limited.

The effects of the intervention were evaluated by telephone interviews using a standardised questionnaire based on the Nordic Occupational Skin Questionnaire (NOSQ-2002) with modified and additional questions on exposure, preventive measures, and knowledge of prevention of skin problems. The relevance and validity of the use of self-reported eczema and questionnaires in skin disease epidemiology have been explained and discussed in the publications by the Nordic Occupational Skin Questionnaire Group, which developed NOSQ-2002. ${ }^{19}{ }^{20}$ Results from validation studies indicate that data from questionnaires are more likely to underestimate than overestimate the true prevalence of hand eczema. Furthermore, in a recent study, clinical validation of questionnaire data on dermatitis showed that for all participants reporting a current skin problem, this was confirmed. Among those not reporting skin problems (the false negatives), mainly milder cases were found. ${ }^{23}$ Self-

Table 5 Information on prevention of skin problems among employees at intervention departments and comparison departments

\begin{tabular}{|c|c|c|c|c|c|c|c|c|}
\hline & \multicolumn{2}{|c|}{$\begin{array}{l}\text { Intervention group } \\
(n=136)\end{array}$} & \multicolumn{2}{|c|}{$\begin{array}{l}\text { Comparison group } \\
(\mathrm{n}=\mathbf{2 8 0})\end{array}$} & \multicolumn{2}{|c|}{$\begin{array}{l}\text { Stopped as gut cleaners } \\
(\mathrm{n}=79)\end{array}$} & \multicolumn{2}{|l|}{$\begin{array}{l}\text { Total } \\
(\mathrm{n}=495)\end{array}$} \\
\hline & Baseline & Follow up & Baseline & Follow up & Baseline & Follow up & Baseline & Follow up \\
\hline $\begin{array}{l}\text { Have had information on prevention of } \\
\text { occupational skin problems }\end{array}$ & $60.3 \%(82)$ & $76.1 \% * *(102)$ & $52.9 \%(148)$ & $62.3 \%(170)$ & $54.4 \%(43)$ & n.r. & $55.2 \%(273)$ & n.r. \\
\hline Relative change $\%$ & \multicolumn{2}{|c|}{$+26.2 \%+(p<0.005)$} & \multicolumn{2}{|c|}{$+17.8 \%+(p<0.005)$} & n.r. & n.r. & n.r. & n.r. \\
\hline $\begin{array}{l}\text { Prevention of occupational skin problems } \\
\text { are discussed at the workplace }\end{array}$ & $58.8 \%(80)$ & $82.2 \%{ }^{* *}(111)$ & $55.9 \%(156)$ & $54.4 \% * *(148)$ & $53.2 \%(42)$ & n.r. & $56.3 \%(218)$ & n.r. \\
\hline Relative change $\%$ & \multicolumn{2}{|c|}{$+40.0 \%+(p<0.005)$} & \multicolumn{2}{|c|}{$-2.7 \%$ (not significant) } & n.r. & n.r. & n.r. & n.r. \\
\hline
\end{tabular}

Results expressed as \% (number).

**Significant difference between intervention and comparison and "stopped as gut cleaners" $(p<0.01)$.

†Significant difference between baseline and follow up.

n.r., not relevant. 


\section{Main messages}

- At one year follow up the eczema frequency among gut cleaners at the intervention departments shoved a $27 \%$ relative reduction.

- The prevention programme aimed at reducing occupational skin problems among workers with wet work proved feasible to implement.

- The eczema frequency was reduced, although the duration of wet work could not be reduced substantially.

reported eczema was preferred to a symptom based eczema definition, as studies have shown this to be more consistent with clinical examinations when made with questions comparable to those used in the present study..$^{24-27}$

A strength of the present study is that in contrast to other intervention studies carried out in wet work occupations, this study was designed with a one year follow up. Primarily the one year follow up was selected to eliminate the effects of seasonal variations in skin diseases activity and exposure. The second reason for the one year follow up was to make sure that the intervention activities were implemented at least three months before the follow up interviews were carried out.

The present intervention study is a field study with a study design close to real world conditions-that is, the number of intervention departments and the duration of intervention activities were adjusted to a level accepted by the company management, which paid for all work time expenses. The only expenses covered by the research project budget were additional costs for effect evaluation, development of the educational programme, and the time used by the consultants from the research team. Thus, the company management's willingness to pay can be seen as an indicator of motivation to support and implement the intervention activities.

The effect modifying influence of investigators being present at the workplaces can be regarded as minimal in this study as the intervention activities where the researchers were present at the workplaces only involved members of the local project groups. The personal interviews collecting data for the process evaluation were conducted after the follow up telephone interviews were carried out. All other data collection was similar for the intervention group and the comparison group.

Evidence based prevention programmes should be continuously revised and improved in order to include new scientific results. Based on experiences from the intervention activities, the process evaluation, and the results presented in this paper, the recommendations in the prevention programme introduced at the workplaces concerning the use of disinfectants and the application of skin care products were revised (see box 1).

The study group is obviously a high risk group for hand eczema. A similar relative reduction of eczema might not be achievable in groups with a lower risk. In groups with a different tradition of skin prevention at baseline, the intervention might lead to results differing from ours. But it is remarkable that work related skin problems can be reduced by proper preventive measures, although the working conditions in the gut cleaning departments for most of the employees imply nearly full time exposure to wet work, skin irritants, and relatively high hygienic demands, with minimal possibility to reduce the exposure.

\section{Policy implications}

- Occupational skin diseases in wet work occupations should not be accepted as inevitable.

- Implementation of effective prevention programmes is feasible.

- Prevention programmes should be revised on a regular basis to include the latest scientific results.

\section{Authors' affiliations}

M-A Flyvholm, K Mygind, L Sell, K F Jepsen, National Institute of Occupational Health, Copenhagen, Denmark

A Jensen, Department of Occupational and Environmental Medicine, Haderslev Hospital, Denmark

Funding: The project was financially supported by an appropriation for prevention of asthma and allergy, administered by the Danish Ministry of Health

Competing interests: none declared

\section{REFERENCES}

1 Arbejdsskadestyrelsen. Industrial injury statistics 2003 (1997-2003) [in Danish]. Copenhagen: Arbejdsskadestyrelsen, 2004:1-35.

2 Diepgen TL, Coenraads PJ. The epidemiology of occupational contact dermatitis. Int Arch Occup Environ Health 1999;72:496-506.

3 Flyvholm M-A, Borg L, Burr H. Skin problems. Work environment in Denmark 2000 [in Danish]. 1-19.2001. Copenhagen: National Institute of Occupational Health, 2001.

4 Flyvholm M-A, Borg L. Skin problems among employees included in the Danish work environment cohort study 2000. In: Alanko K, Hannuksela M, Nordman $\mathrm{H}$, et al. Final programme \& abstract book. First world congress on work-related and environmental allergy (1st WOREAL); 2003 July 9-12; Helsinki, Finland. Helsinki: Finnish Institute of Occupational health, 2003:67.

5 Diepgen TL. Occupational skin-disease data in Europe. Int Arch Occup Environ Health 2003;76:331-8.

6 Halkier-Sørensen L. Occupational skin diseases. Contact Dermatitis 1996;35(suppl 1):1-120.

7 Adisesh A, Meyer JD, Cherry NM. Prognosis and work absence due to occupational contact dermatitis. Contact Dermatitis 2002;46:273-9.

8 Hutchings CV, Shum KW, Gawkrodger DJ. Occupational contact dermatitis has an appreciable impact on quality of life. Contact Dermatitis $2001 ; 45: 17-20$.

9 Wallenhammar LM, Nyfiäll M, Lindberg M, et al. Health-related quality of life and hand eczema-a comparison of two instruments, including factor analysis. J Invest Dermatol 2004;122:1381-9.

10 Hayashi $M$, Saitoh $M$, Fujii $N$, et al. Dermatoses among poultry slaughterhouse workers. Am J Ind Med 1989;15:601-5.

11 Schwanitz HJ, Riehl U, Schlesinger T, et al. Skin care management: educational aspects. Int Arch Occup Environ Health 2003:76:374-81.

12 Flyvholm M-A, Harborg I. Prevention program for food handlers. An intervention study. Allergologie 1995;18:457.

13 Flyvholm M-A, Harborg I. Prevention program for food handlers. 45. Nordisk Arbejdsmiliømøde, Rebild Bakker, Danmark 1-3 September 1997. 1997:19-20.

14 Held E, Wolff C, Gyntelberg F, et al. Prevention of work-related skin problems in student auxiliary nurses: an intervention study. Contact Dermatitis 2001;44:297-303.

15 Held E, Mygind K, Wolff C, et al. Prevention of work related skin problems: an intervention study in wet work employees. Occup Environ Med 2002;59:556-61.

16 Agner T, Held E. Skin protection programmes. Contact Dermatitis 2002;47:253-6.

17 Flyvholm M-A, Jepsen KF, eds. Documentation report on risk factors and prevention of work-related skin diseases in wet work occupations [in Danish]. Copenhagen: National Institute of Occupational Health, AMI Dokumentation $15,2004$.

18 Ford JK, Fisher S. The transfer of safety training in work organizations: a systems perspective to continuous learning. Occup Med 1994;9:241-59.

19 Flyvholm M-A, Susitaival P, Meding B, et al. Nordic occupational skin questionnaire-NOSQ-2002. Nordic questionnaire for surveying workrelated skin diseases on hands and forearms and relevant exposures. Copenhagen: Nordic Council of Ministers, 2002:1-186.

20 Susitaival P, Flyvholm M-A, Meding B, et al. Nordic occupational skin questionnaire (NOSQ-2002): a new tool for surveying occupational skin diseases and exposure. Contact Dermatitis 2003;49:70-6.

21 Altman DG. Practical statistics for medical research. Boca Raton: Chapman \& Hall/CRC, 1999. 
22 Andersen EB, Jensen N-E, Kousgaard N. Teoretisk statistik for økonomer. Copenhagen: Akademisk forlag, 1989.

23 Livesley EJ, Rushton L, English JS, et al. Clinical examinations to validate selfcompletion questionnaires: dermatitis in the UK printing industry. Contact Dermatitis 2002;47:7-13.

24 Svensson $\AA$, Lindberg M, Meding B, et al. Self-reported hand eczema: symptom-based reports do not increase the validity of diagnosis. $\mathrm{Br} J$ Dermatol 2002;147:281-4
25 Yngveson M, Svensson Å, Isacsson A. Evaluation of a self-reported questionnaire on hand dermatosis in secondary school children. Acta Derm Venereol 1997;77:455-7.

26 Vermeulen R, Kromhout H, Bruynzeel DP, et al. Ascertainment of hand dermatitis using a symptom-based questionnaire; applicability in an industrial population. Contact Dermatitis 2000;42:202-6.

27 Smit HA, Coenraads PJ, Lavrijsen AP, et al. Evaluation of a self-administered questionnaire on hand dermatitis. Contact Dermatitis 1992;26:11-16. 